\title{
New modified hook device for endoloop closure of the mucosal defect after gastric endoscopic submucosal dissection
}

Closing the submucosal defect after gastric endoscopic submucosal dissection (ESD) may reduce postoperative adverse events [1]. In recent years, various methods for mucosal closure after gastric ESD have been developed [2,3]. However, gastric mucosal defect closure is difficult as the submucosa and muscularis are thicker than in other parts of the digestive tract. Recently, mucosal defect closure using an endoloop was reported [4]. However, it is not common in Japan, and it is difficult to grasp and tighten the length of the endoloop because it is not fixed. Therefore, we developed a new and modified hook device for endoloop closure to grasp the endoloop tail.

The modified hook device is created from the hook device of the endoloop (HX-400U-30; Olympus, Tokyo, Japan). First, the hook part of the hook device is cut. The wire is then bent bluntly into a "J" shape. This new modified hook device makes it easier to grasp the endoloop tail. Video 1 shows how to make the new modified hook device, followed by its use for closure of an actual mucosal defect after ESD.

One of our patients had an early gastric cancer of $50 \mathrm{~mm}$ in diameter. ESD was performed to resect the lesion. We initially used the clip-on-clip closure method [5] to reduce the mucosal defect area after ESD but could not achieve complete closure. Therefore, we tried closing the mucosal defect using the new modified hook device for endoloop closure. First, the endoloop was fixed with clips around the mucosal defect. Thereafter, the endoloop tail was grasped with the new modified hook device, and the mucosal defect was then closed. In this patient, the mucosal defect was large; however, complete closure of the mucosal defect after ESD using two endoloops was possible ( $\mathbf{F i g . 1}$ ). The patient was discharged without any postoperative adverse events.

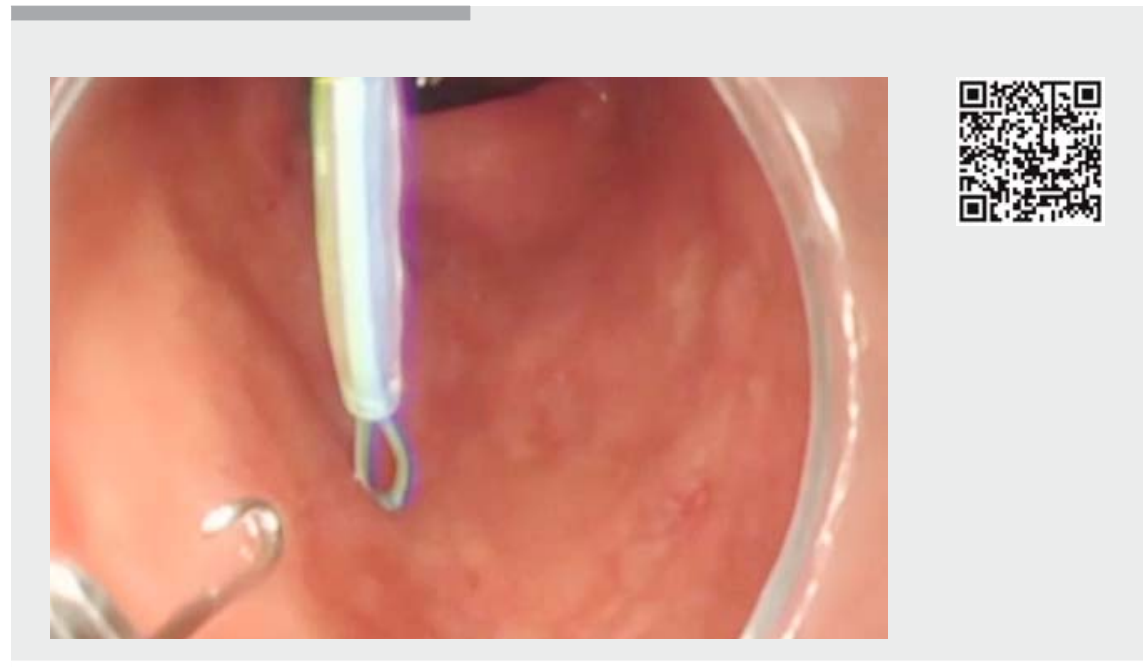

$\checkmark$ Video 1 Video showing how to make the new modified hook device and its use to close an actual submucosal defect after endoscopic submucosal dissection.

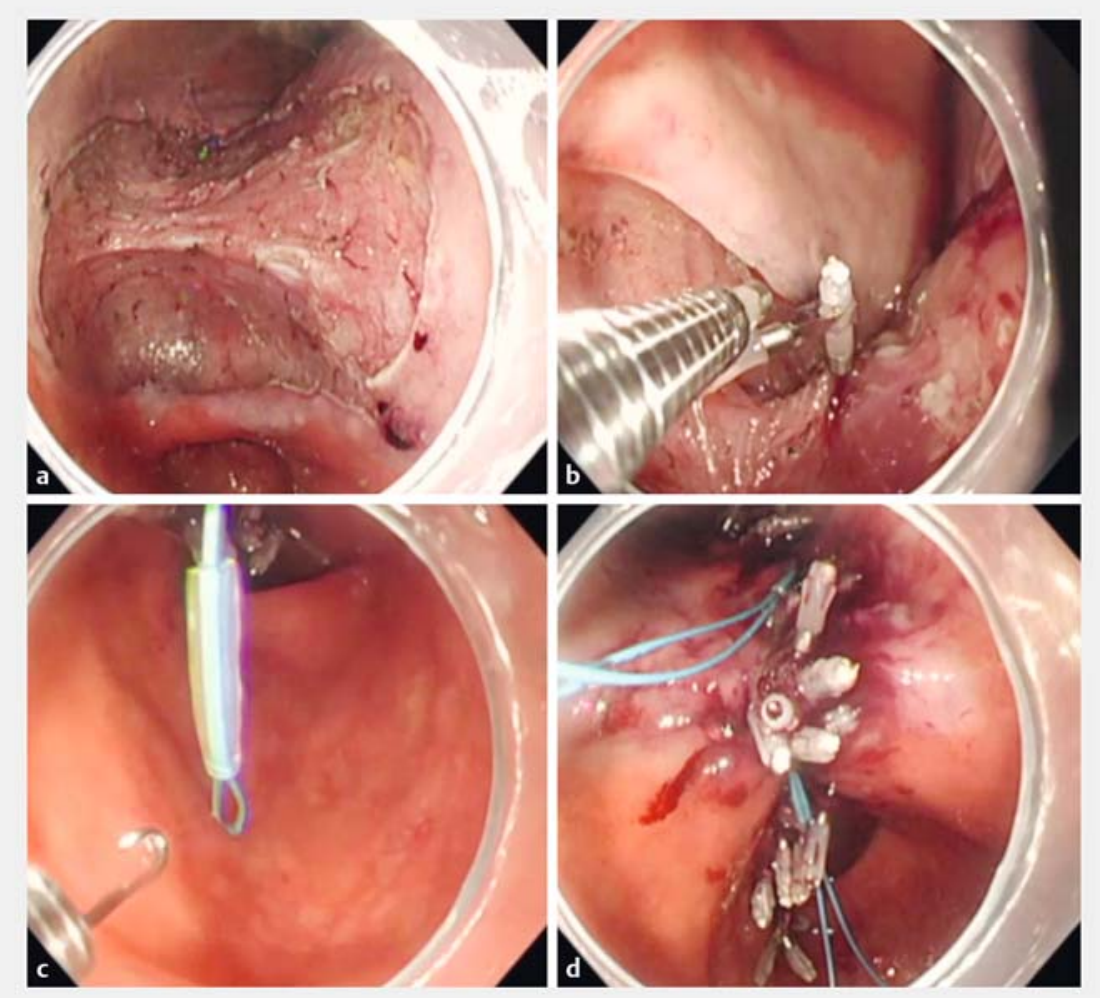

- Fig. 1 Endoscopic views showing: a the mucosal defect after endoscopic submucosal dissection (ESD) of an early gastric cancer ( $50 \mathrm{~mm}$ in diameter); $\mathbf{b}$ closure with the clip-on-clip closure method using a normal clip on the mucosal defect; $\mathbf{c}$ the endoloop tail being grasped using the new modified hook device; $\mathbf{d}$ the post-ESD mucosal defect after its successful closure with two endoloops. 
This new modified hook device makes it possible to grasp the endoloop tail more safely and easily.

Endoscopy_UCTN_Code_CPL_1AJ_2AG

\section{Competing interests}

None

The authors

Tatsuma Nomura ${ }^{1,2}$, Akira Kamei², Shinya Sugimoto ${ }^{2}$, Takaaki Morikawa ${ }^{1}$, Jun Oyamda ${ }^{2}$

1 Department of Gastroenterology, Kinan Hospital, Minamimuro, Mie, Japan

2 Department of Gastroenterology, Ise Red Cross Hospital, Ise, Japan

\section{Corresponding author}

\section{Tatsuma Nomura, MD}

Department of Gastroenterology, Kinan Hospital, 4750 Atawa, Mihama-cho, Minamimuro-gun, Mie 519-5293, Japan Fax: +815-9792-3357

m06076tn@icloud.com

\section{References}

[1] Choi KD, Jung HY, Lee GH et al. Application of metal hemoclips for closure of endoscopic mucosal resection-induced ulcers of the stomach to prevent delayed bleeding. Surg Endosc 2008; 22: 1882 - 1886

[2] Goto O, Sasaki M, Ishii H et al. A new endoscopic closure method for gastric mucosal defects- feasibility of endoscopic hand suturing in an ex vivo porcine model (with video). Endosc Int Open 2014; 2: E111 -E116

[3] Yamasaki Y, Takeuchi Y, Kato M et al. Lineassisted complete closure of large gastric mucosal defects by use of multiple clip-andline technique. Gastrointest Endosc 2016; 1: $49-50$

[4] Lua GW, Lie F. Closure of a large mucosal defect after endoscopic submucosal dissection using "pre-detached loop and clips" method with a single-channel gastroscope. Endoscopy 2015; 47: E464 - E465

[5] Nomura T, Kamei A, Sugimoto $S$ et al. New closure method for a mucosal defect after endoscopic submucosal dissection: the clipon-clip closure method. Endoscopy. doi:10.1055/s-0044-100486

\section{Bibliography}

DOI https://doi.org/10.1055/a-0624-2016

Published online: 12.6.2018

Endoscopy 2018; 50: E222-E223

(c) Georg Thieme Verlag KG

Stuttgart · New York

ISSN 0013-726X

\section{ENDOSCOPY E-VIDEOS}

https://eref.thieme.de/e-videos

口回 Endoscopy E-Videos is a free access online section, reporting 回钴 on interesting cases and new

techniques in gastroenterological endoscopy. All papers include a high quality video and all contributions are freely accessible online.

This section has its own submission website at https://mc.manuscriptcentral.com/e-videos 